\title{
In vitro effects of bufotenine against RNA and DNA viruses
}

\author{
Camila Mosca Barboza ${ }^{1,2}$ D . Daniel Carvalho Pimenta ${ }^{3} \cdot$ Hugo Vigerelli $^{4} \cdot$ Andréa de Cássia Rodrigues da Silva $^{1}$. \\ Jaíne Gonçalves Garcia ${ }^{1,2}$ - Raphaela Mello Zamudio ${ }^{1,2}$ - Juliana Galera Castilho ${ }^{1}$ Jarbas Alves Montanha ${ }^{5}$. \\ Paulo Michel Roehe ${ }^{6} \cdot$ Helena Beatriz de Carvalho Ruthner Batista ${ }^{1,2}$
}

Received: 11 December 2020 / Accepted: 19 September 2021 / Published online: 25 September 2021

(c) Sociedade Brasileira de Microbiologia 2021

\begin{abstract}
Bufotenine, an alkaloid that can be found in plant extracts and skin secretions of amphibians, is reported to have potential antiviral activity. The present study evaluated the antiviral activity of bufotenine against different genetic lineages of rabies virus (RABV, a single-stranded, negative-sense RNA virus), canine coronavirus ( $\mathrm{CCoV}$, a positive-sense RNA virus) and two double-stranded DNA viruses (two strains of herpes simplex virus type 1/HSV-1 [KOS and the acyclovir-resistant HSV-1 strain 29R] and canine adenovirus 2, CAV-2). The maximal non-toxic bufotenine concentrations in Vero and BHK-21 cells were determined by MTT assays. The antiviral activity of bufotenine against each virus was assessed by examination of reductions in infectious virus titres and plaque assays. All experiments were performed with and without bufotenine, and the results were compared. Bufotenine demonstrated significant RABV inhibitory activity. No antiviral action was observed against CCoV, CAV-2 or HSV-1. These findings indicate that the antiviral activity of bufotenine is somewhat linked to the particular infectious dose used and the genetic lineage of the virus, although the mechanisms of its effects remain undetermined.
\end{abstract}

Keywords Rabies $\cdot$ Herpesvirus $\cdot$ Adenovirus $\cdot$ Coronavirus $\cdot$ Alkaloid $\cdot$ Bufotenine

\section{Introduction}

Viruses infect all types of organisms, from archaea to unicellular bacteria and animals; currently, more than 6.500 species of viruses have been described [1]. Most viruses are apathogenic to their hosts. On occasion, disease may occur as unwanted collateral damage from viral infections;

Responsible Editor: Giliane Souza Trindade

Camila Mosca Barboza

cml_mb@hotmail.com

Instituto Pasteur, Av. Paulista, São Paulo 393, Brazil

2 Universidade Federal Do ABC, Santo André, Brazil

3 Laboratório de Bioquímica E Biofísica, Instituto Butantan, São Paulo, SP, Brazil

4 Laboratório de Genética, Instituto Butantan, São Paulo, SP, Brazil

5 Departamento de Produção E Matéria-Prima - Faculdade de Farmácia da Universidade Federal Do Rio Grande Do Sul, Porto Alegre, RS, Brazil

6 Instituto de Ciências Básicas da Saúde/Universidade Federal Do Rio Grande Do Sul, Porto Alegre, RS, Brazil however, in their ideal form, parasitism, viral infections should bring no harm to either the virus or its host. Because of inadequate adaptation, particular disease conditions eventually become associated with defined viral infections. Illnesses can be caused by RNA viruses such as rabies virus (Rabies lyssavirus, RABV) and canine coronavirus (Alphacoronavirus $1, \mathrm{CCoV}$ ) or DNA viruses such as human herpesvirus type 1 (Human alphaherpesvirus 1, HSV-1) and canine adenovirus type 2 (Canine mastadenovirus A, CAV-2). Many other viruses have been identified as aetiological agents of diseases; in the last year, severe acute respiratory syndrome coronavirus 2 (SARS-CoV-2) was identified as responsible for COVID-19, a globally pandemic respiratory disease [2]. The dissemination of SARS-CoV-2 sparked studies seeking to develop vaccines, antivirals or identify new potential antiviral actions of different agents. Unfortunately, to date, antiviral agents have been successfully developed for only a few virus, such as herpesvirus, hepatitis B virus, hepatitis C virus and influenza virus [3]. As such, there is still an urgent need for molecules that present antiviral potential [4].

Antiviral agents can be found in different sources, such as marine organisms, in which the first agent against human immunodeficiency virus (HIV), AZT, was identified [5, 6]. 
Another potential source of antiviral agents is plants such as Maytenus ilicifolia, Ilex theezans and Ilex brevicuspis, native species from South Brazil that show antiviral activity against HSV-1 [7]. Among these, alkaloids have been evaluated as antivirals on a number of occasions, such as berberine, which reduces chikungunya virus, human cytomegalovirus, human papillomavirus, HSV and HIV infection $[8,9]$. Alkaloids are secondary compounds that have been identified predominantly in plants and less frequently from fungi and animals. Alkaloids have an extensive range of biological activities, including, in some cases, antiviral properties [10]. Here, we focused on the potential antiviral activity of bufotenine, an indole alkaloid that occurs naturally in plants and amphibians. Indole alkaloids can interact with cellular receptors to act as agonists or antagonists. The antiviral activity of bufotenine on RABV was first described by Vigerelli [11-14]. However, here, a study was conducted to determine the antiviral activity of bufotenine against viruses with different mechanisms of replication, including negative- and positive-sense RNA viruses (RABV and CCoV) and double-stranded DNA viruses (HSV-1 and CAV-2).

\section{Materials and methods}

\section{Bufotenine}

The alkaloid was purified from Anadenanthera colubrina seeds as described by Vigerelli et al. (2014) [11] and initially diluted in Eagle's minimal essential medium (E-MEM) containing 10\% heat-inactivated foetal bovine serum (FBS) to a $9 \mathrm{mg} / \mathrm{mL}$ concentration. The preparation was stored at $4{ }^{\circ} \mathrm{C}$ until use.

\section{Viruses}

All viruses described below were propagated in the respective cell lines as described in the Cell lines section, collected and stored at $-80^{\circ} \mathrm{C}$ for subsequent experiments.

\section{RNA viruses}

Four genetic lineages of rabies virus (RABV) were used: a genetic lineage from the insectivorous bat Eptesicus furinalis (964/06), a genetic lineage from the haematophagous bat Desmodus rotundus (4005/10), a genetic lineage from the wild dog Cerdocyon thous (4871/11) and a genetic lineage from the domestic dog Canis lupus familiaris (3629/11). In addition, strain MAV \#795 of the RNA canine coronavirus $(\mathrm{CCoV})$ was used.

\section{DNA viruses}

The following DNA viruses were used: the herpesvirus type 1 (HSV-1) strains KOS (University of Rennes, France) and acyclovir-resistant HSV-1 strain 29R and the canine adenovirus type 2 (CAV-2) strain Toronto A26/61.

\section{Cell lines}

Baby hamster kidney cells (BHK-21, originally ATCC CCL-100) were used to propagate RABV, while African green monkey kidney cells (Vero, originally ATCC CCL81) were used to propagate CCoV, HSV-1 and CAV-2. The cells were cultured in E-MEM containing $10 \%$ heatinactivated FBS and maintained at $37{ }^{\circ} \mathrm{C}$ in a humidified $5 \% \mathrm{CO}_{2}$ atmosphere.

\section{Cytotoxicity assay}

The cytotoxicity of bufotenine towards uninfected cells was evaluated with an MTT (3-4,5-dimethythiazol-2yl)2,5-diphenyl tetrazolium bromide) assay. Different concentrations of bufotenine $(4.0,2.0,1.0$ and $0.5 \mathrm{mg} / \mathrm{mL})$ were added to 96 -well microplates seeded with $5 \times 10^{5}$ cells/well of either BHK-21 or Vero cells. For a positive cytotoxicity control, 20\% dimethyl sulfoxide (DMSO) was added to the culture medium. The negative controls included cells overlaid with cell culture medium only. After $24 \mathrm{~h}$ at $37^{\circ} \mathrm{C}$, the medium was removed, and $50 \mu \mathrm{L}$ of MTT $(5 \mathrm{mg} / \mathrm{mL}$ in E-MEM without FBS) was added to the plates, which were then incubated at $37{ }^{\circ} \mathrm{C}$ for $4 \mathrm{~h}$. After incubation, the MTT solution was removed, and $100 \mu \mathrm{L}$ of DMSO was added to each well to solubilize the formazan crystals. After gently shaking the plates, the crystals were completely dissolved, and the absorbances were measured in a spectrophotometer (Abs $540 \mathrm{~nm}$ ).

\section{Antiviral activity}

The antiviral activity of bufotenine for each virus was assessed on the basis of the reductions in infectious virus titres (Reductions in infectious virus titres section) and plaque counts (Plaque assay section). All experiments were performed in quadruplicate with and without bufotenine according to concentration previously determined by the MTT assay (Cytotoxicity assay section), and the results were compared. Bufotenine was prepared according to the previously determined concentration described in Cytotoxicity assay section. 


\section{Reductions in infectious virus titres}

Virus titres were determined by limiting dilution and are expressed as the $50 \%$ tissue culture infection dose per 50 $\mu \mathrm{L}\left(\mathrm{TCID}_{50}\right)$ according to Reed and Müench, 1938 [15]. Briefly, virus stocks were prepared in tenfold dilutions $\left(10^{-1}\right.$ to $10^{-7}$ ) in E-MEM, and $50 \mu \mathrm{L}$ of stock was added to the wells of 96-well microplates in quadruplicate. Subsequently, $50 \mu \mathrm{L}$ of a cell suspension containing $5.0 \times 10^{5} \mathrm{cells} / \mathrm{mL}$ was added. The plates were then incubated at $37^{\circ} \mathrm{C}$ in a humidified $5 \% \mathrm{CO}_{2}$ atmosphere for 72 to $120 \mathrm{~h}$. For visualization of RABV antigens, cells were stained as described below (section Direct fluorescent antibody (dFA) test for detection of RABV antigens). The plates were examined daily in search of evidence of cytopathic effects of CCoV, CAV-2 and HSV-1 with the aid of an optical microscope.

Direct fluorescent antibody (dFA) test for the detection of RABV antigens After $72 \mathrm{~h}$, the medium was removed by aspiration, and the BHK-21 cells were fixed by adding cold $80 \%$ acetone $(200 \mu \mathrm{L})$. After $30 \mathrm{~min}$, the acetone was discarded by inversion, and the microplates were dried. Next, an anti-rabies IgG/fluorescein isothiocyanate conjugate (Pasteur Institute) was added as previously described [16]. After this period, the plates were washed three times with phosphate-buffered saline (PBS) and then three more times with distilled water. Finally, $50 \mu \mathrm{L}$ of $10 \%$ glycerine was added to each well, and the plates were examined under an inverted fluorescence microscope.

\section{Plaque assay}

Briefly, confluent cell monolayers prepared on 96-well plates were infected with $0.1,1,10$ and 100 plaque-forming units (PFU) of RABV, CCoV and CAV-2 in $50 \mu \mathrm{L}$ of inoculum with and without bufotenine and grown for 72 to $120 \mathrm{~h}$. For HSV-1, the assay was performed in 6-well plates. Vero cells were seeded $24 \mathrm{~h}$ before infection, and then $0.1,1,10$ and $100 \mathrm{PFU}$, bufotenine and $0.3 \%$ agarose in E-MEM supplemented with FBS were added. Plaques were stained with Coomassie blue. For visualization of RABV antigens, the cells were stained as described above (section Direct fluorescent antibody (dFA) test for detection of RABV antigens). The plates were examined daily in search of evidence of cytopathic effects of $\mathrm{CCoV}$ and CAV-2 with the aid of an optical microscope.

\section{Statistical analysis}

The $50 \%$ cytotoxic concentration $\left(\mathrm{CC}_{50}\right)$ was estimated by a non-linear regression analysis of the concentration-effect curves. Multiple comparisons were performed using oneway ANOVA. Comparisons between the "with bufotenine" and "without bufotenine" groups were performed using Student's $t$ test. Statistical significance was accepted at $p<0.05$, and the analyses were performed using GraphPad Prism version 5.0 software for Windows.

\section{Results}

\section{Cytotoxicity assay}

The MTT method was used to measure the cytotoxicity of bufotenine in BHK-21 and Vero cells. As shown in Fig. 1, when bufotenine was used at $0.5 \mathrm{mg} / \mathrm{mL}$, the cell viability was $71 \%$ and $77 \%$ for BHK-21 and Vero cells, respectively. As this was the highest concentration of the drug that induced low cytotoxicity, it was used for all subsequent assays. The $\mathrm{CC}_{50}$ of bufotenine were $0.64 \mathrm{mg} / \mathrm{mL}$ and $0.82 \mathrm{mg} / \mathrm{mL}$ for BHK-21 and Vero cells, respectively.
Fig. 1 Cytotoxicity assay of bufotenine in BHK-21 (A) and Vero $(\mathbf{B})$ cells, as determined by MTT assay. C-, negative control (no bufotenine added); $\mathrm{C}+$, positive cytotoxicity control (E-MEM plus 20\% DMSO)
A

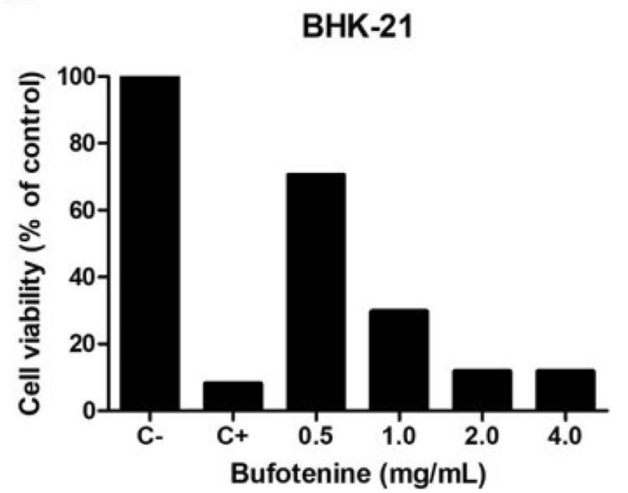

B

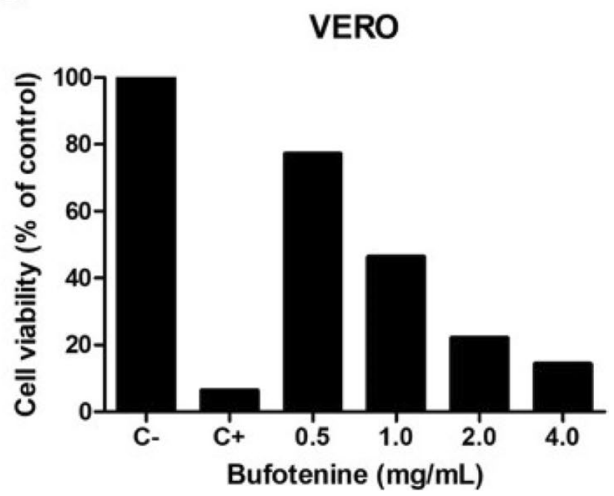




\section{Antiviral activity}

\section{Reductions in infectious virus titres}

Effect of bufotenine on RABV When evaluating the effect of bufotenine on cells infected with different RABV strains, a statistically significant difference in infectious titres was detected with one lineage only (strain 964/06, originating from a non-haematophagous bat, Eptesicus furinalis). There was a $1.7 \log _{10}$ reduction in infectious titre following bufotenine addition. The infectious titres registered with other RABV strains were not significantly affected by the addition of bufotenine (Fig. 2).

Effect of bufotenine on CCoV, HSV-1 and CAV-2 Bufotenine did not inhibit CCoV, HSV-1 or CAV-2. The viral titres with and without bufotenine were similar for these viruses, and no significant reductions in titres were identified.

\section{Plaque assay}

Effect of bufotenine on RABV As shown in Fig. 3, bufotenine had significant effects on all strains of RABV tested when 100 PFU was used. However, when 10 PFU was used, it was also possible to observe significant reductions except in the strain with a genetic lineage from the domestic dog, 3629/11 (Fig. 3B).

Effect of bufotenine on HSV-1 The results regarding the action of bufotenine against the two strains of HSV-1 are shown in Fig. 4. Figure 4A shows the effect of bufotenine against the HSV-1 standard strain KOS. Despite the difference observed between 10 and 100 PFU, with a $23.5 \%$ and $12.9 \%$ reduction, these values were not considered statistically significant. At 1 PFU, no reduction in titres were identified with bufotenine. For acyclovir-resistant HSV-1 strain
29R, no significant reductions were identified with any of the PFUs evaluated (Fig. 4B).

Effects of bufotenine on CCoV and CAV-2 Bufotenine did not inhibit $\mathrm{CCoV}$ or CAV-2. The numbers of viral plaques with and without bufotenine were similar for these viruses for all PFUs used for the experiments.

In Table 1, the action of bufotenine against each studied virus is summarized as determined with the two methods employed.

\section{Discussion}

Viral infections remain major health issues worldwide. In order to combat viruses that have devastating effects on humans and animals, efforts to discover new antiviral compounds have been made. However, the current selection of antivirals approved for clinical use is limited. The majority of antiviral agents currently available have been developed for the treatment of human immunodeficiency virus (HIV) [3].

Bufotenine is an alkaloid whose antiviral activity against RABV has already been identified [11-14]. In the present study, we evaluated the antiviral potential of bufotenine against DNA and RNA viruses that infect humans and animals.

CAV-2 is an important dog pathogen from the Adenoviridae family that is responsible for respiratory disease and is related to secondary infections. The treatment is only symptomatic and supportive [17]. Similarly, $\mathrm{CCoV}$ is another pathogenic agent related to gastroenteritis that in some cases can be fatal, mostly in young dogs. No treatment is available [18]. Thus, there is a great need for the development of antiviral drugs against viral diseases for which no treatments are currently available.

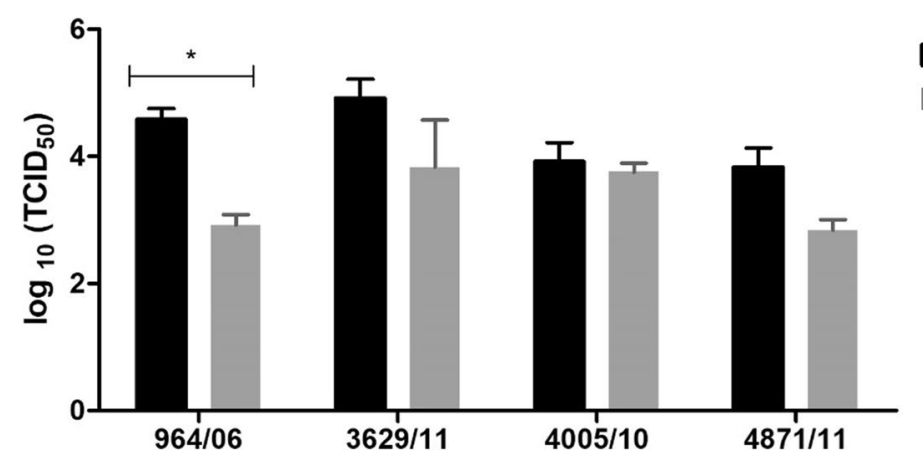

Fig. 2 Effect of bufotenine $(0.5 \mathrm{mg} / \mathrm{mL})$ on infectious titres after $72 \mathrm{~h}$ of different strains of rabies virus (RABV) (964/06, genetic lineage from the insectivorous bat Eptesicus furinalis; 4005/10, genetic lineage from the haematophagous bat Desmodus rotundus; 4871/11, genetic lineage from the wild dog Cerdocyon thous; and 3629/11, genetic lineage from the domestic dog, Canis lupus familiaris) multiplied in BHK-21 cells $(*) P<0.05$ 
A

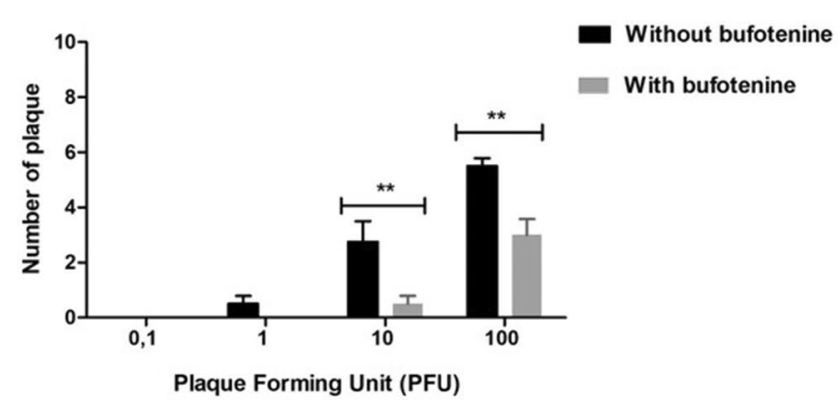

C

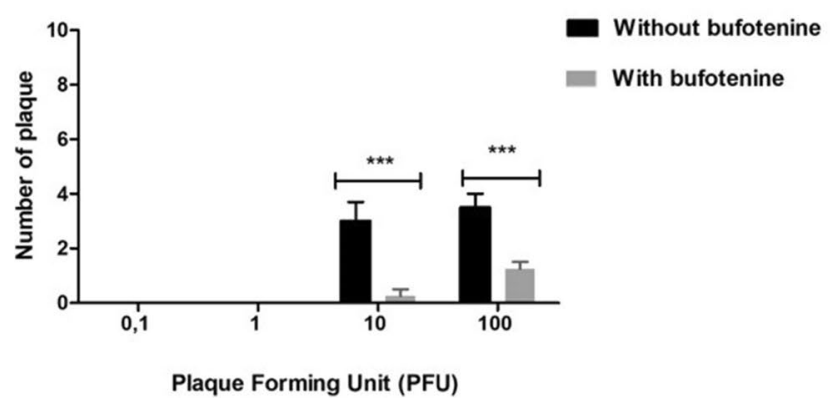

Fig. 3 Effect of bufotenine against different plaque-forming units $(0.1,1,10$ and $100 \mathrm{PFU})$ of rabies virus (RABV) with and without bufotenine after 72 h. A 964/06, genetic lineage from insectivorous bat Eptesicus furinalis, (**) $P<0.01$. B 3629/11, genetic line-

\section{A}

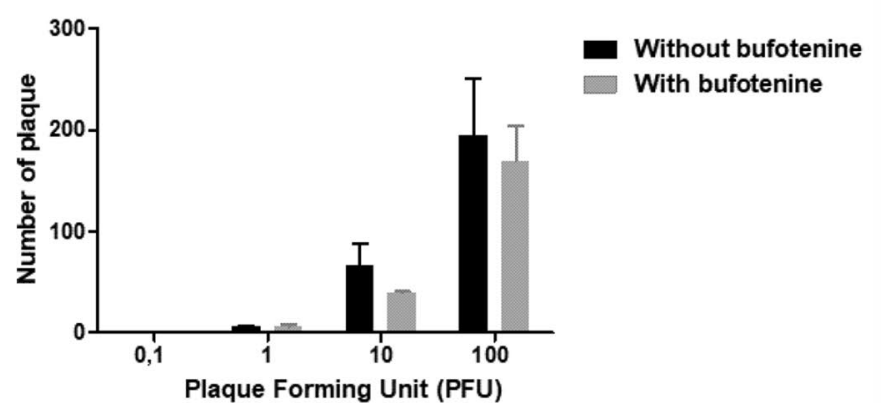

B

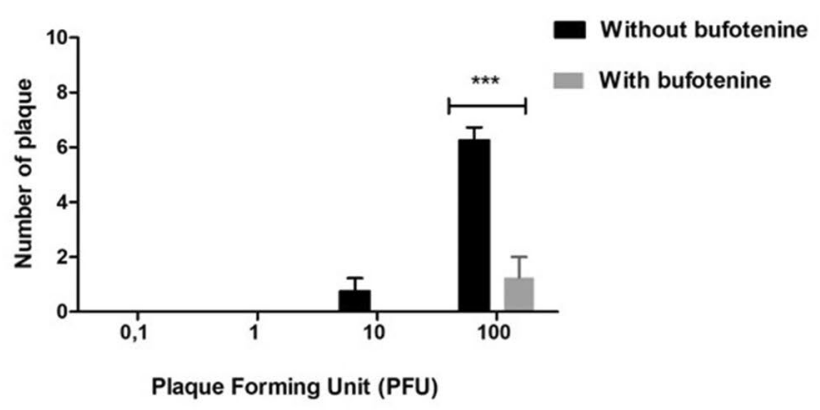

D

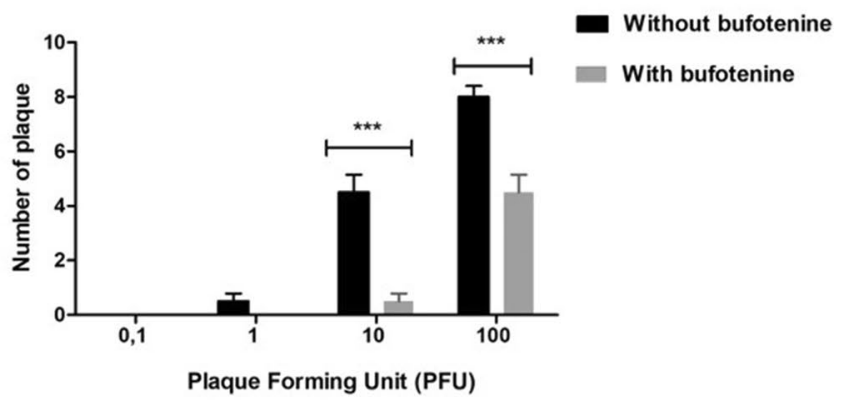

age from domestic dog Canis lupus familiaris (***) $P<0.001$. C $4005 / 10$, genetic lineage from haematophagous bat Desmodus rotundus, (***) $P<0.001$. D 4871/11, genetic lineage from wild dog Cerdocyon thous $(* * *) P<0.001$

\section{B}

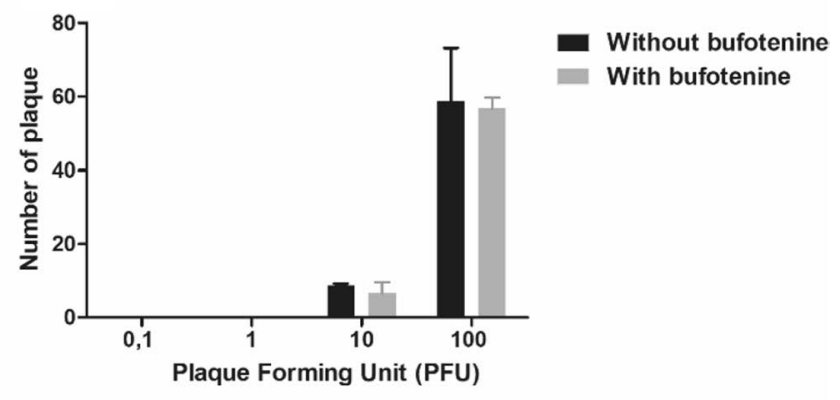

Fig. 4 Effect of bufotenine against different plaque-forming units (100, 10, 1 and 0.1 PFU) of herpesvirus type 1 (HSV-1) with and without bufotenine after $72 \mathrm{~h}$. A KOS strain and B 29-R/acyclovir-resistant strain

Before evaluation of its antiviral activity, the cytotoxic effects of bufotenine were investigated in Vero and BHK-21 cells to determine the maximum non-toxic concentration of bufotenine. For that, an MTT colorimetric assay was used. In this assay, a concentration of $0.5 \mathrm{mg} / \mathrm{mL}$ bufotenine was chosen because it is a concentration that maintains high viability of cells.

Contrary to the findings of Vigerelli et al. (2014) [11], our findings revealed anti-rabies action through difference in viral titration and plaque assays with distinct doses of the virus from distinct genetic lineages of RABV. In titration, compared with the control, bufotenine was able to significantly reduce the non-haematophagous bat (Eptesicus furinalis) titre, although when comparing different doses of the virus, we observed reductions in the numbers of plaques for all lineages of RABV. This finding demonstrates that the action of bufotenine depends on the number of infectious particles. At $10 \mathrm{PFU}$, bufotenine presented the maximum 
Table 1 Summary of the effects of bufotenine against RNA and DNA viruses. The table summarizes all results obtained in antiviral assays (viral titration and plaque assays) for each virus. + , antiviral activity of bufotenine; -, no antiviral activity of bufotenine. *EF, Eptesicus furinalis; CLF, Canis lupus familiaris; DR, Desmodus rotundus; CT, Cerdocyon thous

\begin{tabular}{llllll}
\hline Virus & & Characteristic & Sample & $\begin{array}{l}\text { Antiviral activity } \\
\text { viral titration }\end{array}$ & $\begin{array}{l}\text { Antiviral activ- } \\
\text { ity number of } \\
\text { plaques }\end{array}$ \\
\hline RNA & CCoV & Enveloped & A26/61 & - & - \\
& RABV & & $964 / 06(\mathrm{EF})^{*}$ & + & + \\
& & & $3629 / 11(\mathrm{CLF})^{*}$ & - & + \\
& & & $4005 / 10(\mathrm{DR})^{*}$ & - & + \\
& & & $4871 / 11(\mathrm{CT})^{*}$ & - & + \\
DNA & CAV-2 & Nonenveloped & MAV\#795 & - & - \\
& HSV-1 & Enveloped & KOS & - & - \\
& & & 29R, acyclovir- & - & resistant (ACV) \\
& & & &
\end{tabular}

effects in almost all lineages, except the domestic dog lineage, with greater than $80 \%$ reductions in the numbers of plaques. Here, were tested two different methods to identify an antiviral action of bufotenine, viral titration and plaque assay; however, the results were different according to the method used. Perhaps the difference could be explained by the stage of viral replication that bufotenine acts.

The adopted methodologies in this study to evaluate the antiviral action were viral titration and plaque assay. Both are indirect techniques used to quantify infectious particles in unknown samples $[19,20]$. In the viral titration, susceptible cells were inoculated with serial dilutions of the virus with and without bufotenine. In this case, the initial concentration of the virus was unknown. On the other hand, the plaque assay was performed with known concentrations based on the titre obtained previously. Besides that, the plaque assay can demonstrate a macroscopic effect of the interest compound.

Another possible hypothesis is that bufotenine acts extracellularly through competition with viral particles for the cellular receptors used for RABV, as suggested by Vigerelli et al. (2014) [11]. For RABV, some receptors are proposed to be responsible for binding the virus and allowing it into cells. Some of these receptors may be nicotinic acetylcholine receptor (nAChR), neuronal cell adhesion molecule (NCAM) and p75 neurotrophin receptor (p75NTR) [21]. On the other hand, Vigerelli et al. (2020) [13] demonstrated that nAChR does not seem to interact with alkaloids. New investigations are necessary to clarify the relationship between alkaloids and cells.

Although BHK-21 has some neuronal receptors as NCAM, more research is needed to identify the exact mechanism of action of bufotenine in RABV [22, 23]. For other viruses, bufotenine was not able to suppress infection; nevertheless, for the HSV-1 standard strain (KOS), we could observe an effect at 10 PFU, however, with no statistical significance. It is important to highlight the fact that this study only investigated one specie from the Herpesviridae family; future studies could consider the antiviral potential of bufotenine against other members of this family. In addition, associations of bufotenine with other compounds or medications could be explored to potentialize the antiviral effect. Numerous data indicate that the use of combined compounds can be effective in antiviral effects [24-26]. Among the drugs that exhibit inhibitory action against herpesvirus replication, the most commonly used in human medicine are nucleoside analogues; unfortunately, numerous resistance mechanisms have been demonstrated for some of these drugs [27, 28]. Thus, the search for new compounds with alternative mechanisms of action has become necessary.

HSV-1, like RABV, may have neurotropic potential, which could justify the action of bufotenine against these two viruses. Most likely, these two viruses share common molecules or receptors to which bufotenine binds. Vigerelli et al. (2020) indicate that bufotenine probably can interact with other cell structures beyond receptors. Ion channels, proteins and endocytosis can have an important role in the mechanism of action of bufotenine [13]; however, the exact mechanism remains unknown.

Another debatable aspect of bufotenine is the hallucinogenic effects of bufotenine due to similarities to other bioactive molecules such as LSD [29]. However, it has been suggested that the bufotenine cannot cross the blood-brain barrier, due to poor lipid solubility. On the other hand, a study conducted in 2018 by Vigerelli et al. [12] showed the effects in mice of different doses by subcutaneous inoculation. The results demonstrated the alkaloid was found in some organs, including the brain, although without significant effects. The same study associated the use of bufotenine with an increased survival rate of rabid mice from 15 to $40 \%$ [13] being a good candidate as a prototype, once there is no antiviral treatment available for rabies.

Although HSV-1 therapy is available, the treatment consists of blocking viral replication and consequently decreasing the oral lesion. The therapy is not effective on the latency stage, and even with some antiviral agents approved, the resistance phenomenon occurs [30]. Although the rates of 
resistance are low, new alternatives or combined therapy can be an alternative strategy for the patients.

Bufotenine was not effective against CAV-2 or CCoV in the titration or in the plaque assay. A few studies have investigated antiviral action against these viruses, such as an in vitro study conducted by Cueto et al. (2011) [31] on the effect of an extract of propolis against CAV-2, bovine viral diarrhoea virus (BVDV) and feline calicivirus (FCV). The extracts proved to be effective against CAV-2 and BVDV but relatively less effective against FCV.

Similarly, Silva et al. [32] used titration to demonstrate the antiviral activity of $\mathrm{P} 34$ peptide isolated from Bacillus against the animal viruses $\mathrm{CCoV}, \mathrm{CAV}-2$, canine distemper virus (CDV), canine parvovirus type 2 (CPV-2), equine arteritis virus (EAV), equine influenza virus (EIV), feline calicivirus (FCV) and feline herpesvirus type 1 (FHV-1). The peptide was able to reduce the titres of the DNA and RNA viruses FHV-1 and EAV, respectively, but had no effects on $\mathrm{CAV}-2$ and CCoV.

Interestingly, treatment with bufotenine did not affect all viruses equally. Stronger effects were observed against RABV, while weaker effects were observed against HSV-1. This heterogeneous activity might indicate some specificity against distinct types of viruses. Clear differences in activity against DNA versus RNA viruses and enveloped versus nonenveloped viruses were not observed. Therefore, additional experiments might provide further explanations.

\section{Conclusion}

Despite continuous developments in antiviral therapy, viral diseases are still important causes of human and animal death. Since viruses and hosts are intimately related, the design of effective, virus-specific antiviral agents that do not affect host cells has proven to be difficult.

The results of the present investigation provide further evidence of the potential use of alkaloids. The study showed that bufotenine can inhibit RNA (RABV) viruses, depending on the viral load.

Acknowledgements We thank our colleagues Adriana Candido Rodrigues Nasraui, Eliana de Almeida and Rene dos Santos Cunha Neto for all the assistance.

Author contribution All authors contributed to the study conception and design. Material preparation, data collection and analysis were performed by Camila Mosca Barboza, Daniel Carvalho Pimenta, Hugo Vigerelli de Barros, Andréa de Cássia Rodrigues da Silva, Jaíne Gonçalves Garcia, Raphaela Mello Zamudio, Juliana Galera Castilho Kawai, Jarbas Alves Montanha, Paulo Michel Roehe and Helena Beatriz de Carvalho Ruthner Batista. The first draft of the manuscript was written by Camila Mosca Barboza, and all authors commented on previous versions of the manuscript. All authors read and approved the final manuscript.
Funding This study was financed in part by the Coordenação de Aperfeiçoamento de Pessoal de Nível Superior (CAPES), Brazil (Finance Code 001), and by the Pasteur Institute of Sao Paulo, Brazil (IP 03/2019).

Data availability The datasets generated and analysed during the current study are available from the corresponding author on reasonable request.

Code availability Not applicable.

\section{Declarations}

Ethics approval Ethical approval was obtained from the animal ethics committee of the Instituto Pasteur of Sao Paulo, Brazil (16.2018).

Consent to participate Not applicable.

Consent for publication Not applicable.

Conflict of interest The authors declare no competing interests.

\section{References}

1. International Committee on Taxonomy of Viruses (ICTV) (2020). https://talk.ictvonline.org/taxonomy/. Accessed 25 January 2020

2. Phelan A, Katz R, Gostin LO (2020) The novel coronavirus originating in Wuhan, China: challenges for global health governance. JAMA 323:709-710

3. De Clercq E (2004) Antiviral drugs in current clinical use. J Clin Virol 30:115-133

4. Thawabteh A, Juma S, Bader M et al (2019) The biological activity of natural alkaloids against herbivores, cancerous cells and pathogens. Toxins 11:1-28

5. Bergmann W, Feeney RJ (1951) Contributions to the study of marine products. XXXII. The nucleosides of sponges I. J Org Chem 16:981-987

6. Costa-Lotufo LV, Wilke DV, Jimenez PC et al (2009) Organismos marinhos como fonte de novos fármacos: histórico \& perspectivas. Quim Nova 32:703-716

7. Montanha JA, Moellerke P, Bordignon SA et al (2004) Antiviral activity of Brazilian plant extracts. Acta farmacéutica bonaerense 23:183-186

8. Varghese FS, Thaa B, Amrun SN et al (2016) The antiviral alkaloid berberine reduces chikungunya virus-induced mitogen-activated protein kinase signaling. J Virol 90:9743-9757

9. Warowicka A, Nawrot R, Goździcka-Józefiak A (2020) Antiviral activity of berberine. Adv Virol 165:1935-1945

10. Henriques AT, klein-Júnior LC (2017) Alcaloides: generalidades e aspectos básicos In: Simões CMO et al Farmacognosia: do produto natural ao medicamento, 1th artmed, Porto Alegre, pp 305-304

11. Vigerelli H, Sciani JM, Jared C et al (2014) Bufotenine is able to block rabies virus infection in BHK-21 cells. J Venom Anim Toxins Incl Trop Dis 20:1-8

12. Vigerelli H, Sciani JM, Andrea M et al (2018) Biological effects and biodistribution of bufotenine on mice. BioMed Res 2018:1-11

13. Vigerelli H, Sciani JM, Pereira PMC et al (2020) Bufotenine, a tryptophan-derived alkaloid, suppresses the symptoms and increases the survival rate of rabies-infected mice: the development of a pharmacological approach for rabies treatment. J Venom Anim Toxins Incl Trop Dis 26:1-10 
14. dos Santos Cunha Neto R, Vigerelli H, Jared C et al (2015) Synergic effects between ocellatin-F1 and bufotenine on the inhibition of BHK-21 cellular infection by the rabies virus. J Venom Anim Toxins Incl Trop Dis 21:1-8

15. Reed LJ, Muench H (1938) A simple method of estimating fifty per cent endpoints. Am J Epidemiol 27:493-497

16. Caporale GMM, Da SAR, Peixoto ZMP et al (2009) First production of fluorescent anti-ribonucleoproteins conjugate for diagnostic of rabies in Brazil. J Clin Lab Anal 23:7-13

17. Decaro N, Martella V, Buonavoglia C (2008) Canine adenoviruses and herpesvirus. Vet Clin North Am Small Anim Pract 38:799-814

18. Decaro N, Buonavoglia C (2008) An update on canine coronaviruses: viral evolution and pathobiology. Vet Microbiol 132:221-234

19. Payne S (2017) Methods to study viruses. Viruses 2017:37-52. https://doi.org/10.1016/B978-0-12-803109-4.00004-0

20. Yin Y, Xu Y, Ou Z, Yang X, Liu H (2019) An antiviral drug screening system for enterovirus 71 based on an improved plaque assay: a potential high-throughput method. J Med Virol 8:1440-1447

21. Lafon M (2005) Rabies virus receptors. J Neurovirol 11:82-87

22. Thoulouze M-I et al (1998) The neural cell adhesion molecule is a receptor for rabies virus. J Virol 72(9):7181-7190

23. Guo D et al (2014) Proteomic analysis of membrane proteins of vero cells: exploration of potential proteins responsible for virus entry. DNA Cell Biol 33:20-28

24. Park NH et al (1991) Combined synergistic antiherpetic effect of acyclovir and chlorhexidine in vitro. Oral Surg Oral Med Oral Pathol 2:193-196
25. Yadavalli T et al (2020) Pharmaceutically acceptable carboxylic acid-terminated polymers show activity and selectivity against HSV-1 and HSV-2 and synergy with antiviral drugs. ACS Infect Dis 11:2926-2937

26. Ianevski A et al (2020) Identification and tracking of antiviral drug combinations. Viruses 10:1178

27. de Mello CP, Bloom DC, Paixão IC (2016) Herpes simplex virus type-1: replication, latency, reactivation and its antiviral targets. Antivir Ther 21:277-286

28. Kornfeind EM, Visalli RJ (2018) Human herpesvirus portal proteins: structure, function, and antiviral prospects. Rev Med Virol 28:e1972

29. McBride MC (2000) Bufotenine: toward an understanding of possible psychoactive mechanisms. J Psychoactive Drugs 32:321-331

30. Cunningham A et al (2012) Current management and recommendations for access to antiviral therapy of herpes labialis. J Clin Virol 53:6-11

31. Cueto AP, Alves SH, Pilau M et al (2011) Atividade antiviral do extrato de própolis contra o calicivírus felino, adenovírus canino 2 evírus da diarréia viral bovina. Cienc Rural 41:1800-1806

32. Silva DS, de Castro CC, da Silva e Silva F et al (2014) Antiviral activity of a Bacillus sp P34 peptide against pathogenic viruses of domestic animals. Brazilian J Microbiol 45:1089-1094

Publisher's note Springer Nature remains neutral with regard to jurisdictional claims in published maps and institutional affiliations. 